\section{Conflicting Resources in the Contemporary Couple}

\section{Iulian APOST' ${ }^{1}$}

${ }^{1}$ Researcher, Romanian Academy, Institute of Sociology, Bucureşti, Romania.

E-mail: phdiulian@gmail.com
Abstract: Whatever the selection criteria, whatever the type of partners, marital life cannot avoid the experience of conflicts over one or more aspects of conjugality. And if in common thinking, the conflict is always seen as a failure of the marital relationship, the specialized studies look at the states of conflict as natural stages in a marital journey. From their point of view, the conflict must be seen as a moment that highlights the differences between the partners. Many of these differences are only highlighted in concrete life situations, when the marital context reveals them. In therapy, highlighting problems is viewed positively, because their awareness invites partners to understand these differences, to negotiate and to build a system that marks both common and individual values. Therefore, the appearance of the conflict is not a negative aspect, but rather one that is meant to help the partners to know each other better, to negotiate their differences, desires and common values. From ttheir point of view, the concept of conflict is not similar to that of scandal. The study aims to make a foray into the main issues underlying the conflicts of the contemporary couple.

Keywords: conflict, conjugality, mediation, communication, dysfunction.

How to cite: Apostu, I. (2021). Conflicting Resources in the Contemporary Couple. Logos Universality Mentality Education Novelty: Social Sciences, 10(1), 30-38. https://doi.org/10.18662/lumenss/10.1/55 


\section{Conflict - causal issues}

Throughout their married life, each couple goes through conflicting stages and it would be utopian to believe that, as a whole, married life can avoid conflicts.

Marital conflicts are generated by a multitude of causes, some of which stemming out of different values, because the partners have different opinions on the conjugal attitude, while others are linked to functionality, to the role attitude, the degree of relational involvement or the gender attitude.

The partners, even in the case of the homogamous principle of choosing only one conjugal partner, come from environments with different conjugal cultures, with manifestation of different functions for the couple, each trying to develop, in their own couple, the same behaviors that they became socialized to in their own family. Marital conflicts arise when these manifestation of values seem antithetical to those of the other partner, or when they become insufficient for the expectations and needs of the other partner. Here, another problem would be the age difference between the partners. A larger age difference means even more different backgrounds, different marital expectations, different mentalities and often different needs.

The age difference between the partners can be a source of conflict because they belong to different generations and belong to distinct psychophysical and social typologies, with different interests and concerns. An early age at marriage can be a factor of instability when the aspirations and expectations towards family life change and the partners no longer meet these expectations (Mihailescu, 1999, p. 109).

The younger partner may not have the same attitudes toward the relationship as the older one. The older partner often tends to stimulate their partner to assimilate their values, ttheir attitude can have negative effects, causing rejection reactions from those who want more freedom.

Usually, the romantic fusion between two partners with a greater age difference is based on different motivations, expectations, dreams. Each one projects their conjugal relationship through the prism of their own values, values influenced by the cultural system in which each one is socialized. The degree of flexibility also influences the adaptation and the success of the relationship, but the total readiness of one person to accept the values of the other does not exist. Large age gaps imply gaps in attitudes, values, marital expectations, claims regarding the type of interaction, etc. We cannot say, however, that a marital relationship between two partners with a large age gap is in itself a sure failure, but their chance of stability, of building a solidary framework is much diminished compared to their close-aged partners. 
The first years of marriage are also a risky period because the spouses do not know each other well enough and have not fully developed the sense of security, trust, necessary to ensure marital balance and to maintain a positive family atmosphere.

During the marriage period from 0 to 5 years, the confrontations between the newlyweds are generated by the difficulties of adopting and exercising conjugal roles, confrontations that are frequent, natural and disturbing for the harmony of the couple. The couple's partners relate to each other according to the norms of their parents' marital behavior, which leads to comparisons, analogies, frustrations, tensions, conflicts, so that the couple's relationship is exposed to relational failure (Mitrofan \& Ciupercă, 1998, pp. 323-324).

\section{The onset of conjugality - adaptation dilemmas}

At the same time, the first years of marriage can be a risky period also because the couple's interaction and relationship skills are not well established. Therefore, as the partners get to know each other better, the feeling of security and cohesion of the couple increases in intensity, strengthening the feeling of mutual trust that psychologically secures the partners of the conjugal couple (Mitrofan \& Mitrofan, 1991, p. 197).

Analysis of social indicators for 2021 in terms of the percentage of divorces for partners in the age group 20 - 29 years shows that women divorce in a much higher rate than men $(7.15 \%$ men get divorced, while $16.01 \%$ of women divorce). Cross-assessing divorces by age categories, when the man is in the age category 25-29 years and the woman in the age category 20-24 years, the divorce rate is $6.19 \%$ of the total divorces. Conversely, when the woman is in the 25-29 age group and the man in the 20-24 age group, the dissolution rate is $0.96 \%$. (Source: TEMPO Online Base, 2021). This shows a greater difficulty for men in adapting to marriage for marriages in which men are older than their wives. Conversely, the advantage of a higher age than that of the marital partner gives the woman a greater capacity in terms of managing the marital space.

The material situation of the partners of the conjugal couple continues to play an important role in the contemporary society, in the formation but also in the dissolution of the couple. A clarification must be made here. In itself, it is poverty that often brings couples together to find a way out of the impasse. Thus, the issues that create the conflict are those related to the management of material resources, those related to the 
prioritization of expenditures or the lack of solidarity of one of the partners to actively participate in overcoming economic deficiencies.

Also, couples in which only one of the partners has a good financial situation, can get into conflicts because the one who has money considers that the other partner must tolerate more, as they are financially dependent on them. Couples in which both partners have a good financial situation can be dominated by excesses, dissatisfaction and exaggerated desires, which leads to tensions. (Ciuperca, 2000, p. 109)

Money and how it is managed and spent often lead to conflicts, if the partners do not set certain rules from the beginning of the relationship.

Looking in the opposite direction, we cannot say that partners who have a high financial level are deprived of the problems related to the economic situation of the couple. In such situations, financial competition, budgetary individualism, financial independence, or pride are "viruses" that can affect the stability of the marital couple.

From the earliest stages of marriage, there are strong emotional arguments, especially regarding the consolidation and maintenance of the marital relationship for long periods of time. The expectations of the future spouses are not outlined ad-hoc at the beginning of the marriage, but they are influenced by the models of marital conduct offered in the family of affiliation, personal ideals, etc.

Ollie Pocs presents an inventory of expectations that, although unrealistic, can be avoided: "Our marriage will succeed because we have been courting for a long time","a similar situation for us because we are different", "My marriage partner will satisfy all my requirements and demands"," We will never argue", "We have good communication relations, that's why we can discuss all issues" (Pocs, cit. in Mitrofan \& Mitrofan, 1996, pp. 142-145).

When there is no agreement between the expectations of the two spouses, the conflict is imminent. Why do conflicts arise in this case? Because the desires, the expectations of the partners change during the coexistence of the two. A certain degree of conflict is inevitable and normal to occur, but ignoring it, denying it, increases the number of problems the couple faces.

The claim of a long period of courting as a form of guarantee of a successful marriage is utopian. A long period of courting is effective if the partners use the communication resources efficiently, if they are honest and understand their differences, if they manage to resolve their conflicts when they arise, if they are faithful, if they always prove their love, if they understand their needs and feelings etc. Just the passage of time does not always mean good knowledge., Even if some partners have a relationship for 
10 years, it does not mean that they have ten years of getting to know eachother. Sometimes marital conflicts lead to forms of self-protection, isolation, blocking of conflicting messages, so the problems are hidden in themselves and unresolved. Such couples argue in the first 2-3 years countless times, not being able to reach a high a level of cohesion and intimacy.

Excluding divorce because " this will never happen to us " is a good, constructive premise for a relationship. Marital relationships that begin with mistrust, with the awareness of failure are unstable, while living with real or potential fears, are conflicting relationships with deficits in the quality of communication and interaction. However, feeding on a dream that artificially builds the impossibility of failure becomes risky for a couple. Blocking communication, not discussing marital issues for fear of conflict or dissolution is a wrong strategy. The family must be nourished daily with feelings, with concrete facts, with another level of communication and interaction, with respect, openness, acceptance, love, etc. At the same time, the exclusion of divorce, when the relationship can no longer find mediation resources, can be a toxic decision, the partners thus predefining marital failure indefinitely.

\section{Role dysfunctions - impact on conjugal functionality}

Another problem, often encountered in contemporary space, is that of conjugal roles. The traditionalism in which the parents of today's young people lived is a resource that should be better analyzed because the elements of socialization transmitted to the young generation by their parents no longer have much legitimacy in the culture of contemporary conjugality. Current statistics shows a consistent degree of traditionalism, which shows that conjugal modernity in Romania is not fully accepted. A family is all the more cohesive as the distribution of responsibilities is shared fairly between partners. Participation in domestic activities ensures the wellbeing of the family, influencing the balance and harmony of the marital environment (Voinea, 1993, p. 43). Successful fulfillment of marital roles facilitates communication, understanding, trust, and mutual receptivity in taking on family responsibilities and concerns.

Families in which marital roles are partially and unsatisfactorily performed or in which the husband is too little involved in household chores (which leads to a role overload for women) are at increased risk of stress and conflict. In these families, the relationship between the partners is deficient and dysfunctional, leading to and aggravating conflicts whose effects are felt in the professional and social life of the partners. 
Intermotivational conflict is often generated by the inability of the partners to understand that "a functional couple is one in which each partner contributes to the satisfaction of both their own needs and those of the other" (Ciuperca, 2000, p. 237).

Satisfaction of needs is vital to ensure the cohesion of the couple. Both partners need to meet each other's needs for security, solidarity, communication, self-realization, cooperation, trust and mutual decisionmaking. (Mitrofan \& Ciupercă, 1998, p. 264) Unequal satisfaction of these needs leads to frequent disagreements and states of conflict that are difficult to overcome.

According to Eysenck's definition, personality represents "the more or less sustainable organization of a person's character, temperament, intelligence and physique, their organization determines their unique adaptation to the environment." (Eysenck, cit. in Zlate, 2000, p. 240). Personality is the one that is formed and manifested through relationships, it is the one that allows the explanation of the individual's behavior in certain situations. When the personalities of the partners are different, an incompatibility occurs that can lead to conflicts within the couple.

Most often, the high frequency of conflicts between partners correlates with explosiveness, impulsivity and dominance, the long duration of conflicts correlates with suspicion, critical thinking, emotional rigidity while the intensity of conflicts correlates with emotional immaturity and interpretability. Regarding the form of manifestation of conflicts, the manifest ones correlate with impulsive, extroverted, authoritarian features, while the submanifested one correlate with the hyperemotive, introverted structures (Mitrofan \& Ciupercă, 1998, p. 293).

A couple's love life is almost inconceivable in the absence of a healthy and fulfilled sexuality and when various dysfunctions of the sexual life appear, the immediate consequence is the imbalance of the couple's life.

Within the couple, a large part of the conflicts and resentments related to the sexual life, the frequency or the quality of sexual intercourse, are not related to the acts themselves, but to the relationship and the attention that the partners give each other. The gradual cooling of relations between spouses and the perpetuation of sexual failures create a low level of satisfaction of the needs of coexistence and mutual security, endangering the cohesion of the couple (Mitrofan, 1989, p. 122).

Therefore, the best way to approach sexual conflict is to communicate. Only by communicating needs, desires, limits, boundaries can married life be improved. 
Another cause of marital strife is the nature of the trust and, at the same time, the fidelity of the other. When a woman suspects or accuses her partner of flirting or of extramarital affairs, she only turns him away, destroys the permanent love affair she feels she needs so much.

Undermining trust and mutual respect by manifesting feelings and attitudes of jealousy weakens the moral and psychological consistency of marital union, even when infidelity has not occurred (Mitrofan \& Mitrofan, 1996, p. 126). The pressure that jealousy places on the suspicion of potential infidelity censors the intimate space of the partner. He feels trapped in the confusing rules imposed by jealousy out of the woman's desire to receive permanent feedback of fidelity, but the artificially constructed silence is not comfortable for any of the partners. Gradually, the permanent insecurity felt by jealousy, the disappointment, the censorship and the frustration of the other lead to emptying the relationship of content and, in time, either to the dissolution of the relationship or to getting used with living în a state of tension.

When a partner is feeling jealous, it is important that he or she be encouraged to communicate their or her fears and be reassured that he or she is not jealous. Jealousy can be reduced by cultivating mutual trust between the two partners and by intensifying the couple's interaction (Grant, 1997, p. 65). The partner must not start from the premise that the other's jealousy produces dissolution. Transparency in a relationship nourishes the feeling of security, of trust, offers concrete proofs of fidelity. Therefore, the first reaction strategy in the case of jealousy is not to cultivate disappointment, but to stimulate confidence, because jealousy is learned socially and, for this reason, it can be corrected. Of course, extreme cases sabotage marital relations, so that the chance of mediation decreases considerably.

Another conflicting resource has to do with the structure of extended family relationships. The tense relations with the extended family are amplified most of the times when the married young people live together with their parents, in the presence of different models of conjugal roles and because of the involvement of parents in the interpersonal space of the young people, which favors conflicts.

Coexistence with parents-in-law often generates phenomena of poor interaction and communication difficulties between young people, which favors the emergence of conflicts and weakens the harmony and stability of the conjugal couple (Mitrofan \& Ciupercă, 2002, p. 325).

Most of the time, the reactions of the in-law families are involuntary. They are unaware of the relational discomfort they produce by trying to stimulate children's relationships in a certain direction. Their tendency to actively participate in the lives of young people is a culturally assimilated 
attitude from traditional backgrounds. Parents are often aware of the duty to intervene in the proper conduct of their children's family life without realizing that their form of functional co-participation is harmful to the young couple. Therefore, young people should look for the optimal form of interaction with their in-law families, better establishing the boundaries of their own relationships.

If the relationship cannot improve, it is preferable for the two spouses to build a common strategy to limit the involvement of the in-law families (parents, mothers-in-law) in their married life and to delimit their own style of conjugal interaction, in order to lead to mutual satisfaction (Mitrofan \& Ciupercă, 1998, p. 325).

Also, the preoccupation of both partners for their professional career, in association with the physical fatigue, but especially the mental one, favors the appearance of conflicts. By becoming apathetic, bored, uncontrolled, tense, indifferent to married life and bringing professional worries in the sphere of the marital relationship, partners forget the need for communication, romance, all these endangering the harmony of the marital relationship (Mitrofan \& Ciupercă, 2002, pp. 86-87).

Married life is a permanent travel into the intimacy of the other partner, a permanent mutual feedback, a mutual supportive relationship, and by decreasing common time in favor of ones career can lead to a poor affective connection within that couple.

\section{Conclusions}

There is a fear and a reluctance to conflict within the contemporary couple. The fear of creating states of tension between partners lead many to tolerant behaviors or to relational inhibition. Partners are afraid of discussions that can create tension but do not take into account the fact that not discussing issues creates bigger problems over time than avoiding communication and solving them. From another point of view, not discussing problems keeps unhappiness active or latent, often with partners mimicking happiness rather than feeling it.

The fear of discussing issues retains in its latency the very potency of what some partners want to avoid - the conflict. Partners tend to tolerate until tensions become difficult to manage, but the stress response itself becomes a risk to good conflict management.

The role of the conflict is to highlight issues and expose them to negotiation. Confusing the conflict with the scandal becomes the main mistake of the partners. Avoiding conversations widows the couple of essential information about the other's needs or limitations, and the journey 
into intimacy is blocked. Partners establish boundaries of interaction with each other, learn to protect each other, build domination strategies to maintain control, and thus, many couples with high chances of mediating their conflicts end up dissolving rather than rebuilding marital harmony.

\section{References}

Ciupercă, C. (2000). Cuplul modern: intre emancipare și disoluție [The modern couple: between emancipation and dissolution]. Tipoalex Publishing House.

Grant, W. (1998). Rezolvarea conflictelor [Conflict resolution]. Teora.

Mihăilescu, I. (1999). Familia în societățile europene [Family in European Societies]. Bucharest University Press.

Mitrofan, I., \& Ciupercă, C. (1998). Incursiune in psibosociologia şi psibosexologia familiei [Foray into family psychosociology and psychosexology]. Press Mihaela S.R.L.

Mitrofan, I., \& Ciupercă, C. (2002). Psibologia vieții de cuplu: între ilurie și realitate [The psychology of married life: between illusion and reality]. SPER Publishing House.

Mitrofan, I., \& Mitrofan, N. (1996). Elemente de psibologie a cuplului [The psychology of married life: between illusion and reality]. Şansa S.R.L.

Mitrofan, I., \& Mitrofan, N. (1991). Familia de la A la Z [Family from A to Z]. Editura Ştiințifică.

Mitrofan, I. (1989). Cuplul conjugal - armonie şi dizarmonie [Marital couple - harmony and disharmony]. Ştiințifică şi Enciclopedică

Voinea, M. (1993). Sociologia familiei [Family Sociology]. Bucharest University Press.

Zlate, M. (2000). Fundamentele psihologiei [Fundamentals of psychology]. Pro Humanitate. 